\title{
molecules
}

ISSN 1420-3049

www.mdpi.com/journal/molecules

Review

\section{Organic Nitrates: Past, Present and Future}

\author{
Maria S. França-Silva ${ }^{1}$, Camille M. Balarini ${ }^{2}$, Josiane C. Cruz ${ }^{1}$, Barkat A. Khan ${ }^{3}$, \\ Pabulo H. Rampelotto ${ }^{4, *}$ and Valdir A. Braga ${ }^{1, *}$
}

1 Biotechnology Center, Federal University of Paraíba, João Pessoa, PB 58037-760, Brazil

2 Health Sciences Center, Federal University of Paraíba, João Pessoa, PB 58037-760, Brazil

3 Faculty of Pharmacy and Alternative Medicine, The Islamia University of Bahawalpur, Bahawalpur 63100, Pakistan

4 Interdisciplinary Center for Biotechnology Research, Federal University of Pampa, Antônio Trilha Avenue, P.O. Box 1847, São Gabriel, RS 97300-000, Brazil

* Authors to whom correspondence should be addressed;

E-Mails: p.rampelotto@mail.ufsm.br (P.H.R.);valdir@cbiotec.ufpb.br (V.A.B).

Received: 7 July 2014; in revised form: 31 August 2014 / Accepted: 12 September 2014 /

Published: 24 September 2014

\begin{abstract}
Nitric oxide (NO) is one of the most important vasodilator molecules produced by the endothelium. It has already been established that NO/cGMP signaling pathway deficiencies are involved in the pathophysiological mechanisms of many cardiovascular diseases. In this context, the development of NO-releasing drugs for therapeutic use appears to be an effective alternative to replace the deficient endogenous NO and mimic the role of this molecule in the body. Organic nitrates represent the oldest class of NO donors that have been clinically used. Considering that tolerance can occur when these drugs are applied chronically, the search for new compounds of this class with lower tolerance potential is increasing. Here, we briefly discuss the mechanisms involved in nitrate tolerance and highlight some achievements from our group in the development of new organic nitrates and their preclinical application in cardiovascular disorders.
\end{abstract}

Keywords: organics nitrates; nitrate tolerance; 1,3-dibutoxy-2-propyl nitrate 


\section{Introduction}

Nitric oxide (NO) is a volatile, multifunctional free radical with a short life span. It is synthesized by one of three isoforms of nitric oxide synthase and exerts its effect by the activation of the soluble glunylate cyclase (sGC), which culminates in the production of cyclic guanosine monophosphate (cGMP) and the activation of the cGMP-dependent kinase (PKG) [1,2]. It has been described that a reduction in NO bioavailability is involved in the pathophysiology of many cardiovascular diseases (CVD). In this context, the use of drugs capable of releasing NO is an effective approach while dealing with CVD [3].

Organic nitrates represent the oldest class of NO donors applied clinically. Among them, glyceryl trinitrate (GTN) is the main representative of the class, which also includes isosorbide dinitrate (ISDN), isosorbide 5-mononitrate (ISMN) and pentaerythritol tetranitrate (PETN) [4]. Despite the benefits of thesemolecules in treating CVD like angina pectoris, pulmonary hypertension and heart failure, their continued use may cause tolerance, which is, in fact, the main limitation to the use of organic nitrates $[5,6]$. Here we briefly discuss the past and the present perspectives in organic nitrates and highlight some preclinical tests performed by our group with a novel organic nitrate.

\section{Historical Perspective: The Past}

Glyceryl trinitrate, the first organic nitrate, was discovered in 1847 by Ascanio Sobrero. At that time, it was already described that headacheswere an unpleasant side effect of thissubstance [7]. In 1879, the English physician William Murrel described, for the first time, the beneficial effects of the GTN against angina pectoris [8]. Since then, GTN was established as a treatment for the relief of chest pain, although the exact mechanism of action of this compound remained obscure for about 100 years [9]. Murad and colleagues described, in 1977, that nitrates needed to release NO to present physiological effects [10]. Nitric oxide was only described as an endothelium-derived relaxing factor in middle 80s [11].

After to the introduction of GTN as a therapeutic agent for the treatment of angina pectoris, other nitro compounds with similar chemical properties have been developed. Most recent studies show that, in addition to angina, GTN and other organic nitrates such as ISDN and ISMN are able to improve left ventricular function in patients with congestive heart failure and pulmonary hypertension. Also, they show favorable effects on left ventricular remodeling after myocardial infarction and silent ischemia, in addition to reducing blood pressure alone or in combination with other drugs $[12,13]$.

\section{Mechanism of Action}

Organicnitrates are potential NO donors in biological systems. In general, they do not exert their effect in cell-free systems and act as pro-drugs that need to be bioactivated by either enzymatic or non-enzymatic pathways to release NO. Enzymatic bioactivation of high-potency nitrates like GTN and PETN (tri- and tetranitrates, respectively) depends on the activity of cytosolic and/or mitochondrial aldehyde dehydrogenase (ALDH2), which converts them into nitrite and the denitrated metabolite. Non-enzymatic bioactivation of GTN involves its reaction with thiols from cysteine and cysteine derivatives or with ascorbate, which promote NO release. In contrast, low-potency nitrates 
such asISMN and ISDN (mono and dinitrates, respectively) undergo activation through a mechanism independent of ALDH2, which usually it occurs in endoplasmic reticulum via P450 enzymes [13-15].

Nitric oxide binds to soluble guanylate cyclase (sGC), leading to an increase in the intracellular concentration of cGMP, which in turn activates a specific cGMP-dependent protein kinase (PKG). Once $\mathrm{PKG}$ is active, it promotes the phosphorylation of diverse substrates like myosin light chain kinase (MLCK), sarco/endoplasmic reticulum $\mathrm{Ca}^{2+}$-ATPase (SERCA), plasma membrane $\mathrm{Ca}^{2+}$-ATPase and $\mathrm{Na}^{+} / \mathrm{Ca}^{2+}$ exchanger. All these events result in vasorelaxation and reduction in peripheral vascular resistance [16-19]. Several authors have presented evidence that the vascular relaxation mediated by $\mathrm{NO}$ can occur also by a mechanism independent of cGMP, due to direct activation of $\mathrm{K}^{+}$channels [20].

\section{Clinical Use of Organic Nitrates: The Present}

\subsection{Angina Pectoris}

Angina can be defined as a chest pain or discomfort, usually attributed to myocardial ischemia. It is commonly associated with coronary heart disease and atherosclerosis, although it can also be related to cardiomyopathy or aortic stenosis. The severity of the discomfort does not necessarily relate to the severity of the underling coronary disease [21]. Angina is considered stable when it shows a regular pattern, being elicited by exertion or emotional stress and the pain is relieved by a few minutes of rest or after the use of nitrates.

Nitrates are the leading therapeutic class of drugs to treat angina pectoris [22]. They have been used even before the cardiovascular properties of NO have been established [7]. Organic nitrates exert their maximal vasodilator effects on venous capacitance vessels and large and medium coronary arteries, while small arterioles are less affected. The venodilation induced by these drugs increase the venous capacitance and reduce cardiac preload, which reduces left ventricular filling pressure and myocardium workload. The oxygen demand tomyocardium decreases and this is the key mechanism involved in the use of this class of drugs in angina [15]. At high doses, nitrates exert arterial vasodilator effects, leading to dilation in epicardial arteries. This promotes a redistribution of coronary blood flow from healthy regions to ischemic areas [23].

Short acting nitrates should be administrated to patients during acute angina pectoris symptoms or immediately before physical exercise to prevent angina. On the other hand, long lasting nitrates are recommended for the treatment of patients who remain symptomatic despite the use of aspirin, statins, beta receptor blockers or calcium antagonists [15].

\subsection{Preeclampsia}

Preeclampsia is a serious multisystem disorder characterized by new onset of hypertension, edema and proteinuria, typically after 20 weeks of pregnancy in otherwise normotensive woman. Although the cause of preeclampsia onset is not yet fully understood, endothelial dysfunction, defective NO synthesis, reduced NO bioavailability and reduced NO-mediated vasodilation play an important role in the pathophysiology of this condition [24-26]. Preeclampsia is associated with a substantive increase in morbidity and mortality for the mother and the baby and its complications usually include eclampsia, stroke, liver or kidney failure in the mother and poor growth and preterm birth for the baby [27]. 
Considering that disruption of NO/cGMP pathway is present in preeclampsia, the use of NO donors can be considered a potential pharmacological approach in this situation. In this context, organic nitrates have been used as a promising alternative to treat preeclampsia and without significant adverse cardiovascular effects. The disadvantage of these drugs relies in the possible tolerance development [25] and the efficiency of these drugs in preventing preeclampsia is controversial. Some studies show that they failed in prevent the establishment of preeclampsia, although other beneficial effects were observed, as the likehood of a complication-free pregnancy, decrease in resistance of blood flow to the placenta and improvement of uteroplacental blood flow [24,26].

The main adverse effect observed in the use of nitrates, especially GTN, is the increased risk of headache, which was sufficient severe to lead to the interruption of the treatment in some cases [27]. The successful use of GTN as a transdermal patch opens new therapeutic perspectives, once this approach has few side effects [26].

\subsection{Pulmonary Hypertension}

Pulmonary hypertension is defined as an increase in mean pulmonary arterial pressure $(>25 \mathrm{mmHg})$ at rest [28]. Pulmonary hypertension is a severe and progressive disorder in which the pressure in the pulmonary arteries is increased due to sustained increase in pulmonary arterial resistance. It also culminates in progressive right ventricular dysfunction and death [7,29]. Although drugs aiming to increase vasodilation in pulmonary arteries have been used to treat pulmonary hypertension (for instance prostacyclin, endothelin receptor antagonists, phospodiesterase type 5 inhibitors) [29], organic nitrates have only been proposed as promising alternatives in experimental studies.

In this context, it has already been shown that organic nitrates are capable not only to exert direct vasodilator effects but also to inhibit the synthesis of pulmonary vasoconstrictors such as endothelin 1 and platelet-derived growth factor [30]. Brandler and colleagues successfully used a novel inhaled volatile organic nitrate in an experimental model [31]. They observed that the new compound was effective in promoting the relaxation of constricted pulmonary arteries and in alleviation of pulmonary hypertension. Further studies are necessary to establish the optimal dosing and long-term effects, however, this molecule holds the potential to be an alternative to inhaled NO, which presents toxicity issues and potential drawbacks [31].

\section{New Perspectives: The Future}

Nitrate tolerance is characterized by a reduction in the vasodilator effect of NO donors and the requirement of higher doses. Experimental approaches revealed that organic nitrates such as GTN, ISMN and ISDN induce tolerance. This phenomenon is not yet completely understood and may have several causes such as impaired bioactivation of the drug, desensitization of sGC/cGMP pathway and increase in reactive oxygen species (ROS), which inactivate both endogenous NO and NO released from nitrovasodilators. Furthermore, the process of tolerance is associated with the appearance of unfavorable cardiovascular changes such as increase in sympathetic activity and endothelial dysfunction. Apparently, the only organic nitrate in clinical used which does not induce tolerance or endothelial dysfunction is PETN. In fact, the antioxidant properties of this drug may be responsible, at least in part, for this advantageous characteristic [13,32-34]. 
Considering that tolerance is the major limiting factor to clinical use of this class of drugs and that there is only one organic nitrate clinically available that does not induce tolerance, the search of new compounds unable to induce this undesirable effect has been increasing. Our group has recently evaluated new organic nitrates obtained from glycerin, which molecular structures can be observed in Figure 1.

Figure 1. Structural formula of the new organic nitrates obtained from glycerin [35].

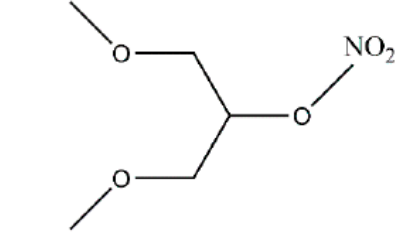

1,2-dimethoxy-2-propyl nitrate

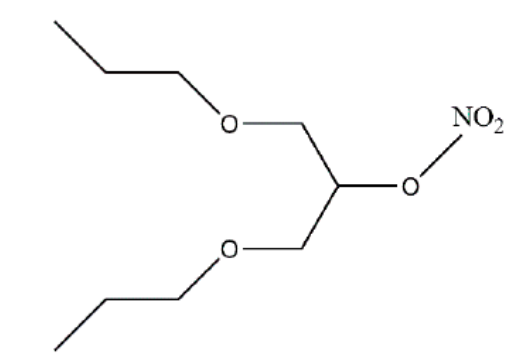

1,2-dipropoxy-2-propyl nitrate

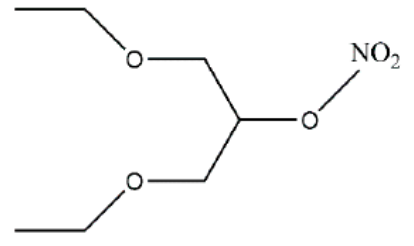

1,2-diethoxy-2-propyl nitrate

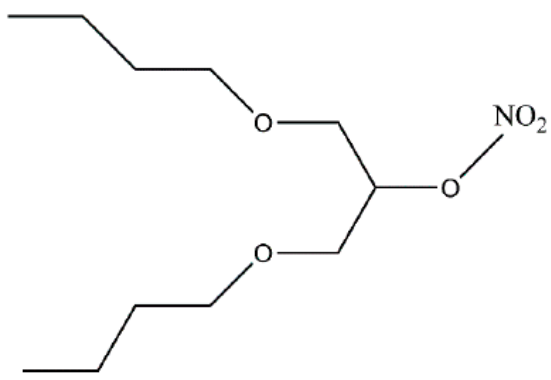

1,2-dibuthoxy-2-propyl nitrate

Our first goal was to evaluate if these molecules could induce vascular relaxation, the main effect of organic nitrates. For this purpose, we performed concentration-response curves of the new NO donors in resistance rings of superior mesenteric artery from rats. We observed that all four compounds were able to induce vasorelaxation in a dose-dependent manner both in the presence or absence of functional endothelium, as shown in Table 1 and Figure 2.

Table 1. Maximum effect $(\mathrm{ME})$ and sensibility $\left(\mathrm{pD}_{2}\right)$ values regarding the vasorelaxant effect of the new organic nitrates derived from glycerin in superior mesenteric artery isolated from rats precontracted with phenyleprine, in the presence or absence of functional endothelium ( $\mathrm{n}=6$ for each group) [35].

\begin{tabular}{cccccc}
\hline \multirow{2}{*}{ Compound } & \multicolumn{2}{c}{ Intact Endothelium } & & \multicolumn{2}{c}{ Denuded Endothelium } \\
\cline { 2 - 3 } \cline { 5 - 6 } & $\mathbf{( \% )} \mathbf{M E} \pm \mathbf{S E M}$ & $\mathbf{p D}_{\mathbf{2}} \pm \mathbf{S E M}$ & & $\mathbf{( \% )} \mathbf{M E} \pm \mathbf{S E M}$ & $\mathbf{p D}_{\mathbf{2}} \pm \mathbf{S E M}$ \\
\hline NDMP & $88.5 \pm 11.2$ & $4.7 \pm 0.13$ & & $93.8 \pm 11.7$ & $4.4 \pm 0.07$ \\
$\mathrm{NDEP}$ & $94.1 \pm 6.7$ & $4.6 \pm 0.08$ & & $108.8 \pm 5.4$ & $4.8 \pm 0.06$ \\
$\mathrm{NDPP}$ & $96.4 \pm 8.3$ & $5.5 \pm 0.10$ & & $111.1 \pm 8.5$ & $5.4 \pm 0.08$ \\
$\mathrm{NDBP}$ & $89.5 \pm 3.4$ & $5.8 \pm 0.10$ & & $105.4 \pm 2.7$ & $5.9 \pm 0.06$ \\
\hline
\end{tabular}

Apparently, the vasodilator response tended to increase as the length of the organic chain added to glycerin increased. Because of that, we have focused our work on 1,3-dibutoxy-2-propyl nitrate 
(NDBP), which has a molecular formula of $\mathrm{C}_{11} \mathrm{H}_{23} \mathrm{NO}_{5}$ and a molecular weight of 249.3. Scheme 1 shows the steps of NDBP synthesis.

Figure 2. Concentration-response curves to new organic nitrates synthetized by our group $\left(10^{-8}-10^{-4} \mathrm{M}\right.$ or $\left.3 \times 10^{-4} \mathrm{M}\right)$ in rat mesenteric artery rings $(\mathrm{n}=6$ per group). The vasorelaxant effect is expressed as a percentage of relaxation of phenylephrine-induced contraction [35].
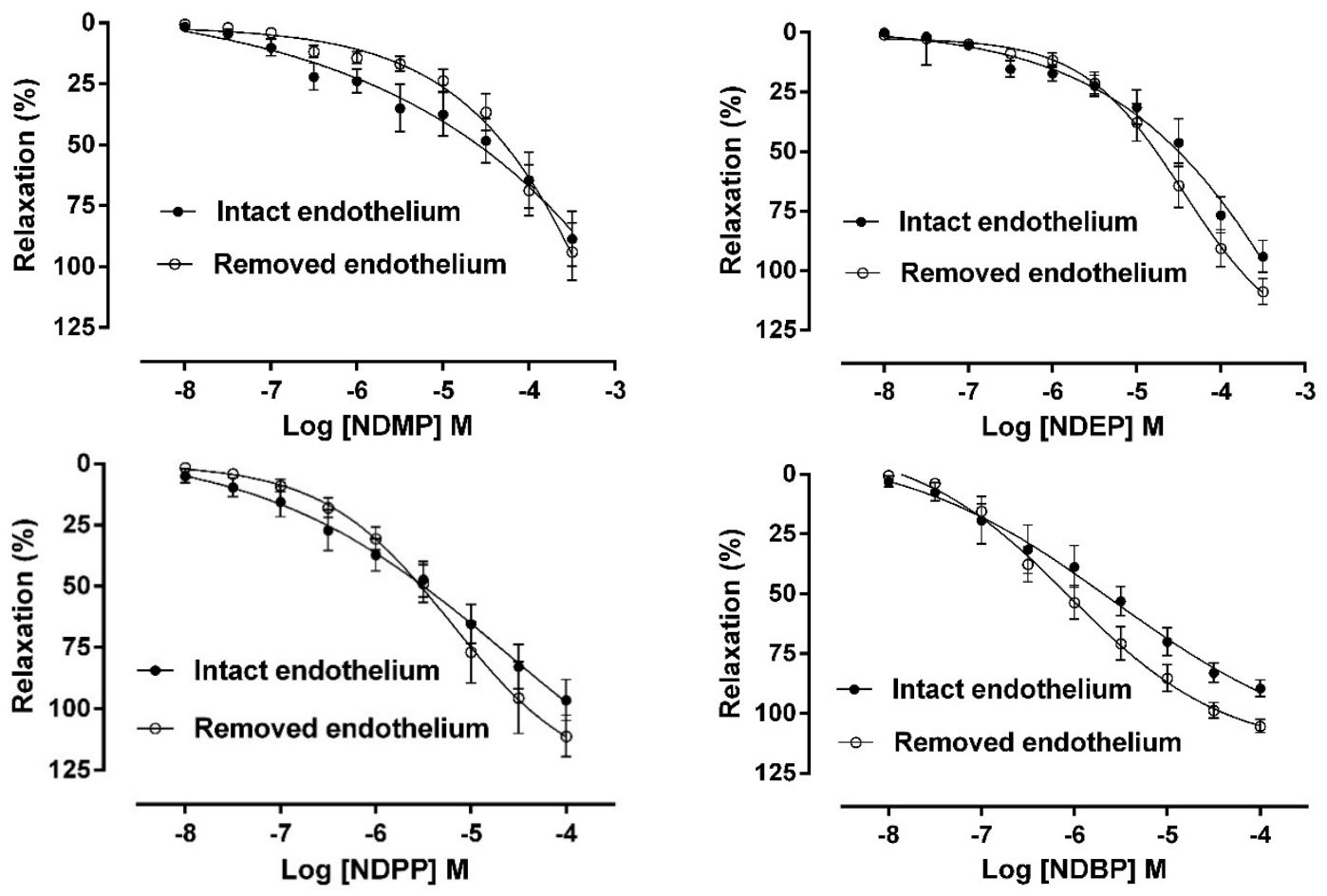

Scheme 1. Synthesis of 1,3-dibutoxy-2-propyl nitrate [36].

A)<smiles>CC(CO)C(O)CO</smiles><smiles>OC(CCl)CCl</smiles>

(1,3-diclorine-propan-2-ol)

B)<smiles>OC(CCl)CCl</smiles>
RONa
Sodium
alkoxide*

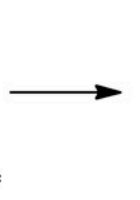<smiles>[2H]CC(O)C[18O]</smiles>

C)<smiles>OCC(O)CO</smiles>
1,3-diether-propan-2-ol $\mathrm{HNO}_{3} / \mathrm{AC}_{2} \mathrm{O}$

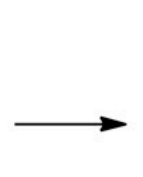<smiles>[R]CC(CO)O[N+](=O)[O-]</smiles>

2-nitrate-1,3-dibuthoxypropan

Using an in vitro pharmacological approach based on simultaneously use of NDBP and blockage of diverse steps of $\mathrm{NO} / \mathrm{sGC} / \mathrm{cGMP}$ pathway, we identified that vasorelaxation induced by NDBP is dependent of NO release, activation of sGC, generation of cGMP and activation of potassium 
channels [34], which is in accordance to what is expected from a NO-releasing drug. It was observed that NDBP is capable of increasing NO bioavailability in cultured vascular smooth muscle cells like other NO donors, such as GTN (Figure 3).

Figure 3. Nitric oxide generation by NDPB in vascular smooth muscle cells. ${ }^{*} p<0.05$ versus basal fluorescence; \# versus $\operatorname{NDBP}\left(10^{-6} \mathrm{M}\right)$ and NDBP $\left(3 \times 10^{-5} \mathrm{M}\right)$. Values are shown as mean \pm S.E.M.

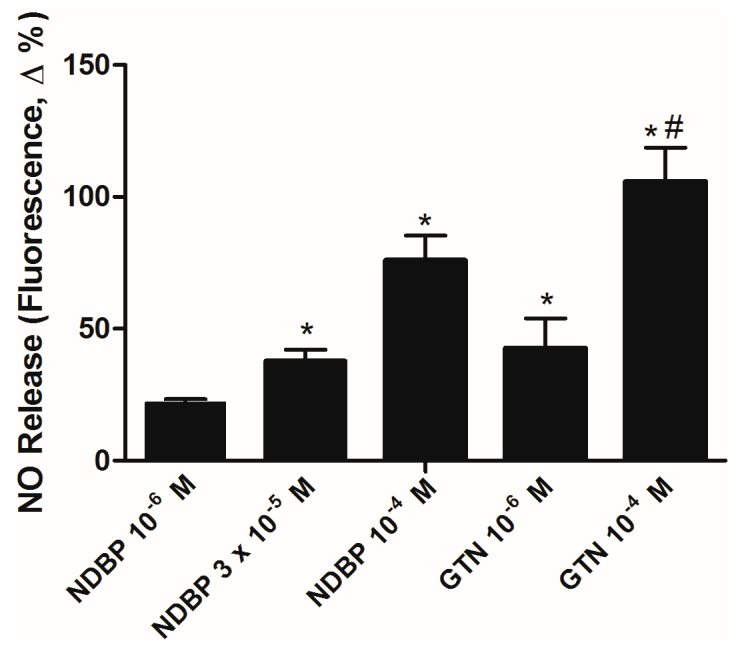

Considering that NDBP could be an alternative option to existing organic nitrates, our second goal was to analyze the effects of NDPB in vivo. Preclinical trials using five different doses of NDBP showed that the new compound presented hypotensive and bradicardic effects in a dose-dependent manner in normotensive and hypertensive non-anesthetized rats. These effects are of interest in a potential new NO donor, once the classical drugs of this class like GTN and sodium nitroprusside (SNP) can cause reflex tachycardia as a side effect. Parasympathetic blockage with atropine or vagotomy suggests that the reduction in blood pressure observed after NDPB administration depends not only to peripheral vasodilation but also to reduction in cardiac output due to increase in parasympathetic tone to the heart [36]. Further studies revealed that cardiovascular responses evoked by NDBP in vivo are dependent of NO release. When a NO-scavenger was used, both bradycardia and hypotension were attenuated [37].

Tolerance is one of the most important undesirable effects evoked by organic nitrates and is responsible for limiting the clinical use of this class of drugs. Thus, our third goal was to evaluate the ability of NDBP to induce tolerance, as previously described [35,38]. Preclinical in vitro approaches revealed that exposition of mesenteric artery rings to NDBP $(10 \mu \mathrm{M}$ or $100 \mu \mathrm{M})$ for 30 min prior to concentration-responses curves to this substance did not alter the vasorelaxant response, suggesting that NDBP did not induced tolerance [35].

Studies by our research group showed that intravenous treatment with NDBP $(5 \mathrm{mg} / \mathrm{kg})$ for three days did not affect vascular reactivity of superior mesenteric artery isolated from normotensive rats to cumulative addition of acetylcholine or SNP (unpublished data), suggesting that continuous exposure to NDBP, at least in the experimental conditions used, does not cause endothelial dysfunction or desensibilization of vascular smooth muscle to NO. From this data we can infer that treatment with NDBP for three days does not induce tolerance in the vascular preparation used, although more studies 
are needed to elucidate this phenomenon. One possible mechanism is that NDBP, like PETN, presents antioxidant properties.

\section{Conclusions}

Since deficiency in $\mathrm{NO} / \mathrm{sGC} / \mathrm{cGMP}$ pathway is involved in many pathological features of cardiovascular system, the use of NO-releasing drugs can figure as an option to treat these conditions. Nitric oxide donors are widely applied in clinical practice despite their undesirable effects, like tolerance. Recently, our group has developed a new organic nitrate with potential to be used clinically in cardiovascular disorders. Preclinical studies confirmed NDBP ability to release NO, leading to vasodilation. Besides, NDBP appears to also act in central nervous system to increase parasympathetic drive to the heart, culminating in reduced blood pressure. This new organic nitrate does not seem to induce tolerance neither endothelial dysfunction in vitro, suggesting that this molecule can figure as a new potential therapeutic approach for cardiovascular disorders. Further studies in vivo are required to investigate the effect of continuous treatment with NDBP on vascular oxidative stress in normotensive and hypertensive conditions and the ability of the compound to prevent pseudotolerance, other common effect of organic nitrates.

\section{Author Contributions}

Maria França-Silva worked in preparing the entire manuscript and conducting experimental trials cited in the text. Camille Balarini and Josiane Cruz helped in writing about clinical use of nitrates. Barkat Khan and Pabulo Rampelotto helped in the writing of the initial topics of this review. Valdir Braga supervised the writing of the article and execution of experimental tests with the new organic nitrates.

\section{Conflicts of Interest}

The authors declare no conflict of interest.

\section{References}

1. Moncada, S.; Higgs, A. Mechanisms of disease: The L-arginine-nitric oxide pathway. N. Engl. J. Med. 1993, 329, 2002-2012.

2. Rudolph, V.; Freeman, B.A. Cardiovascular consequences when nitric oxide and lipid signaling converge. Circ. Res. 2009, 105, 511-522.

3. Pörsti, I.; Paakkari, I. Nitric oxide-based possibilities for pharmacotherapy. Ann. Med. 1995, 27, 407-420.

4. Wang, P.G.; Xian, M.; Tang, X.; Wu, X.; Wen, Z.; Cai, T.; Janczuk, A.J. Nitric oxide donors: Chemical activities and biological applications. Chem. Rev. 2002, 102, 1091-1134.

5. Miller, M.R.; Wadsworth, R.M. Understanding organic nitrates-A vein hope? Br. J. Pharmacol. 2009, 157, 565-567.

6. Münzel, T.; Daiber, A.; Mülsch, A. Explaining the phenomenon of nitrate tolerance. Circ. Res. 2005, 97, 618-628. 
7. Follmann, M.; Griebenow, N.; Hahn, M.G.; Hartung, I.; Mais, F.J.; Mittendorf, J.; Schäfer, M.; Schirok, H.; Stasch, JP.; Stoll, F.; et al. The chemistry and biology of soluble guanylate cyclase stimulators and activators. Angew. Chem. Int. Ed. Engl. 2013, 52, 9442-9462.

8. Murrel, W. Nitroglycerine as a remedy for angina pectoris. Lancet 1879, 1, 80-81.

9. Marsh, N.; Marsh, A. A short history of nitroglycerine and nitric oxide in pharmacology and physiology. Clin. Exp. Pharmacol. Physiol. 2000, 27, 313-319.

10. Arnold, W.P.; Mittal, C.K.; Katsuki, S.; Murad, F. Nitric oxide activates guanylate cyclase and increases guanosine 3':5'-cyclic monophosphate levels in various tissue preparations. Proc. Natl. Acad. Sci. USA 1977, 74, 3203-3207.

11. Furchgott, R.F. Endothelium-derived relaxing factor: discovery, early studies, and identification as nitric oxide. Biosci. Rep. 1999, 19, 235-251.

12. Bode-Böger, S.M.; Kojda, G. Organic nitrates in cardiovascular disease. Cell. Mol. Biol. 2005, 51, 307-320.

13. Münzel, T.; Daiber, A.; Gori, T. Nitrate therapy: New aspects concerning molecular action and tolerance. Circulation 2011, 123, 2132-2144.

14. Mayer, B.; Beretta, M. The enigma of nitroglycerin bioactivation and nitrate tolerance: News, views and troubles. Br. J. Pharmacol. 2008, 155, 170-184.

15. Münzel, T.; Gori, T. Nitrate therapy and nitrate tolerance in patients with coronary artery disease. Curr. Opin. Pharmacol. 2013, 13, 251-259.

16. Furchgott, R.F. Role of endothelium in responses of vascular smooth muscle. Circ. Res. 1983, 53, 557-573.

17. Hilgers, R.H.; Webb, R.C. Molecular aspects of arterial smooth muscle contraction: Focuson Rho. Exp. Biol. Med. 2005, 230, 829-835.

18. Irvine, J.C.; Favaloro, J.L.; Kemp-Harper, B.K. NO- activates soluble guanylate cyclase and Kv channels to vasodilate resistance arteries. Hypertension 2003, 41, 1301-1307.

19. Vanhoutte, P.M.; Boulanger, C.M. Function of the endothelium in arterial hypertension. Rev. Prat. 1995, 45, 2513-2518.

20. Bolotina, V.M.; Najibi, S.; Palacino, J.J.; Pagano, P.J.; Cohen, R.A. Nitric oxide directly activates calcium-dependent potassium channels in vascular smooth muscle. Nature 1994, 368, 850-853.

21. Fox, K.; Garcia, M.A.; Ardissino, D.; Buszman, P.; Camici, P.G.; Crea, F.; Daly, C.; de Backer, G.; Hjemdahl, P.; Lopez-Sendon, J.; et al. Task Force on the Management of Stable Angina Pectoris of the European Society of Cardiology; ESC Committee for Practice Guidelines (CPG). Guidelines on the management of stable angina pectoris: executive summary. Eur. Heart J. 2006, 27, 1341-1381.

22. Gayet, J.L.; Paganelli, F.; Cohen-Solal, A. Update on the medical treatment of stable angina. Arch. Cardiovasc. Dis. 2011, 104, 536-544.

23. Thadani, U. Nitrate tolerance, rebound, and their clinical relevance in stable angina pectoris, unstable angina and heart failure. Cardiovasc. Drugs Ther. 1997, 10, 735-742.

24. Kalidindi, M.; Velauthar, L.; Khan, K.; Aquilina, J. The role of nitrates in the prevention of preeclampsia: An update. Curr. Opin. Obstet. Gynecol. 2012, 24, 361-367.

25. Johal, T.; Lees, C.C.; Everett, T.R.; Wilkinson, I.B. The nitricoxide pathway and possible therapeutic options in pre-eclampsia. Br. J. Clin. Pharmacol. 2013, doi:10.1111/bcp.12301. 
26. Maul, H.; Longo, M.; Saade, G.R.; Garfield, R.E. Nitricoxide and its role during pregnancy: From ovulation to delivery. Curr. Pharm. Des. 2003, 9, 359-380.

27. Meher, S.; Duley, L. Nitricoxide for preventing pre-eclampsia and its complications. Cochrane Database Syst. Rev. 2007, 18, doi:10.1002/14651858.CD006490.

28. Galiè, N.; Hoeper, M.M.; Humbert, M.; Torbicki, A.; Vachiery, J.L.; Barbera, J.A.; Beghetti, M.; Corris, P.; Gaine, S.; Gibbs, J.S.; et al. Guidelines for the diagnosis and treatment of pulmonary hypertension. Eur. Respir. J. 2009, 34, 1219-1263.

29. O’Callaghan, D.S.; Savale, L.; Montani, D.; Jaïs, X.; Sitbon, O.; Simonneau, G.; Humbert, M. Treatment of pulmonary arterial hypertension with targeted therapies. Nat. Rev. Cardiol. 2011, 8, 526-538.

30. Mentzer, S.J.; Reilly, J.J.; DeCamp, M.; Sugarbaker, D.J.; Faller, D.V. Potential mechanism of vasomotor dysregulation after lung transplantation for primary pulmonary hypertension. J. Heart Lung Transplant. 1995, 14, 387-393.

31. Brandler, M.D.; Powell, S.C.; Craig, D.M.; Quick, G.; McMahon, T.J.; Goldberg, R.N.; Stamler, J.S. A novel inhaled organic nitrate that affects pulmonary vascular tone in a piglet model of hypoxia-induced pulmonary hypertension. Pediatr. Res. 2005, 58, 531-536.

32. Klemenska, E.; Beręsewicz, A. Bioactivation of organic nitrates and the mechanism of nitrate tolerance. Cardiol. J. 2009, 16, 11-19.

33. Dikalov, S.; Fink, B.; Skatchkov, M.; Stalleicken, D.; Bassenge, E. Formation of Reactive Oxygen Species by Pentaerithrityltetranitrate and Glyceryl Trinitrate in Vitro and Development of Nitrate Tolerance. J. Pharmacol. Exp. Ther. 1998, 286, 938-944.

34. França-Silva, M.S.; Luciano, M.N.; Ribeiro, T.P.; Silva, J.S.F.; Santos, A.F.; França, K.C.; Nakao, L.S.; Athayde-Filho, P.F.; Braga, V.A.; Medeiros, I.A. The 2-nitrate-1,3-dibuthoxypropan, a new nitric oxide donor, induces vasorelaxation in mesenteric arteries of the rat. Eur. J. Pharmacol. 2012, 690, 170-175.

35. França-Silva, M.S.; Balarini, C.M.; Cruz, J.C.; Khan, B.A.; Santos, A.F.; Athayde-Filho, P.F.; Braga, V.A. Developing new organic nitrates for treating hypertension: A review. Exp. Clin. Cardiol. 2014, in press.

36. França-Silva, M.S.; Monteiro, M.M.O.; Queiroz, T.M.; Santos, A.F.; Athayde-Filho, P.F.; Braga, V.A. The new nitric oxide donor 2-nitrate-1,3-dibuthoxypropan alters autonomic function in spontaneously hypertensive rats. Auton. Neurosci. 2012, 171, 28-35.

37. Queiroz, T.M.; Mendes-Júnior, L.G.; Guimarães, D.D.; França-Silva, M.S.; Nalivaiko, E.; Braga, V.A. Cardiorespiratory effects induced by 2-nitrate-1,3-dibuthoxypropan are reduced by nitric oxide scavenger in rats. Auton. Neurosci. 2014, 181, 31-36.

38. Daiber, A.; Oelze, M.; Coldewey, M.; Bachschmid, M.; Wenzel, P.; Sydow, K.; Wendt, M.; Kleschyov, A.L.; Stalleicken, D.; Ullrich, V.; et al. Oxidative stress and mitochondrial aldehyde dehydrogenase activity: A comparison of pentaerythritol tetranitrate with other organic nitrates. Mol. Pharmacol. 2004, 66, 1372-1382.

(C) 2014 by the authors; licensee MDPI, Basel, Switzerland. This article is an open access article distributed under the terms and conditions of the Creative Commons Attribution license (http://creativecommons.org/licenses/by/3.0/). 